\title{
Ontogeny of Tumor-Associated Macrophages
}

\author{
Marie Laviron and Alexandre Boissonnas* \\ Sorbonne Université, INSERM, CNRS, Centre d'Immunologie et des Maladies Infectieuses - CIMI, Paris, France
}

Tumor-associated macrophages (TAM) represent the main immune cell population of the tumor microenvironment in most cancer. For decades, TAM have been the focus of intense investigation to understand how they modulate the tumor microenvironment and their implication in therapy failure. One consensus is that TAM are considered to exclusively originate from circulating monocyte precursors released from the bone marrow, fitting the original dogma of tissue-resident macrophage ontogeny. A second consensus proposed that TAM harbor either a classically activated M1 or alternatively activated M2 polarization profile, with almost opposite anti- and pro-tumoral activity respectively. These fundamental pillars are now revised in face of the latest discoveries on macrophage biology. Embryonic-derived macrophages were recently characterized as major contributors to the pool of tissue-resident macrophages in many tissues. Their turnover with macrophages derived from precursors of adult hematopoiesis seems

OPEN ACCESS

Edited by:

Florent Ginhoux,

Singapore Immunology Network (A*STAR), Singapore

Reviewed by:

Jo A. Van Ginderachter, Vrije University Brussel, Belgium Simon Yona,

Hebrew University of Jerusalem, Israel

*Correspondence: Alexandre Boissonnas alexandre.boissonnas@upmc.fr

Specialty section:

This article was submitted to Antigen Presenting Cell Biology, a section of the journal Frontiers in Immunology

Received: 16 May 2019

Accepted: 17 July 2019

Published: 31 July 2019

Citation:

Laviron M and Boissonnas A (2019) Ontogeny of Tumor-Associated Macrophages.

Front. Immunol. 10:1799.

do: 10.3389/fimmu.2019.01799 to follow a regulation at the subtissular level. This has shed light on an ever more complex macrophage diversity in the tumor microenvironment than once thought and raise the question of their respective implication in tumor development compared to classical monocyte-derived macrophages. These recent advances highlight that TAM have actually not fully revealed their usefulness and deserve to be reconsidered. Understanding the link between TAM ontogeny and their various functions in tumor growth and interaction with the immune system represents one of the future challenges for cancer therapy.

Keywords: tumor-associated macrophage (TAM), cancer, ontogeny, monocyte-derived cell, cancer therapeutic

\section{INTRODUCTION}

Tumor-associated macrophages (TAM) represent a major component of the tumor microenvironment (TME) that has been extensively studied in the past decades. They play a major role in tumor growth, metastatic dissemination, and therapy failure. Countless reports have described that TAMs can promote angiogenesis, inhibit the anti-tumor immune response, in particular T-cell-mediated cytotoxicity, support tumor growth, and secrete different factors involved in extracellular matrix (ECM) remodeling thus facilitating tumor cell motility and intravasation (1-6). High TAM infiltration is generally correlated with poor outcomes in several types of cancer, such as breast, ovarian, and lung cancer (7-9). However, in some indications TAM can be associated with enhanced anti-tumor immunity (10-12). Although macrophages were originally described as arising exclusively from circulating monocyte precursors (13), it was shown in the recent years that several organs harbor embryonic-derived populations of resident macrophages (ResMac) that maintain and self-renew throughout adulthood (14-16). This 
new concept challenges the dogma of TAM origin and questions their relative function. TAM subsets were originally classified as tumoricidal vs. tumor-promoting, often referred as M1/M2 macrophages (17), based on the expression of specific markers. However, the wide diversity of TAM cannot be covered by this nomenclature and many subsets express overlapping markers of the M1/M2 polarization (18-20). Whether TAM heterogeneity originates from their high plasticity or rather from independent specific lineages giving rise to multiple populations is still unclear. Although cellular ontogeny can recapitulate parts of the heterogeneity, it appears that environmental cues are also major determinants in cell education. Macrophage diversity would then be the result not only of ontogeny but also of nichespecific signaling events of tumor immunity (21-24). One can thus wonder whether the origin of TAM dictates their role in tumor development and is associated with various functions. This represent a key issue for anti-cancer therapies as these subsets might be differentially targeted regarding their role in tumor development.

\section{MACROPHAGE ORIGIN AND TURNOVER}

Although the precise origin of ResMac is still under debate [For the different models proposed, see review (14)], fate-mapping models highlighted a differential origin of tissue macrophages deriving either from an embryonic precursor (yolk sac, fetal liver) or a monocyte precursor from adult hematopoiesis origin. These precursors seed the tissues in different waves during development and adulthood giving rise to different ResMac. The dynamics of these waves vary between organs, age, and macrophage subsets. In some organs, such as the brain, the lung and the liver, some embryonic-derived ResMac (named here EmD-ResMac) maintain by self-renewal in adults whereas in the gut, the skin, the heart, and the pancreas most subsets are progressively replaced through the differentiation of monocyte precursors from adult hematopoiesis into monocyte-derived ResMac (named here MoD-ResMac) with different turnover rates. The ability of newly recruited macrophages to self-maintain in the tissue and become a ResMac per se is proposed to be tightly regulated by space availability and competition for growth factors in the niche (23).

This turnover appears to be variable among subsets in a given organ and could be induced by exposure to homeostatic environmental cues (e.g., mechanical, metabolic) specific of distinct subtissular regions. In the gut, long-lived macrophages with precise subtissular localization are key regulators of physiological functions (25). In the lungs, alveolar macrophages (AM) originate almost exclusively from yolk-sac derived macrophages and self-maintain throughout adulthood (26) whereas lung interstitial macrophages follow a more complex regulation, unveiling further heterogeneity in this subset $(27,28)$. While some of these interstitial macrophages have an embryonic origin (27), others differentiate from distinct monocyte precursors according to the subtissular niche they colonize, thus becoming the dominant population during adulthood (22). As most studies rest on relative proportion of the different subsets, whether EmD-ResMac are replaced or dominated by MoD-ResMac needs to be confirmed. Along tissue seeding, circulating monocytes undergo significant gene modifications to become truly ResMac sharing strong similarities with their counterpart of embryonic origin. This differentiation is dictated by lineage determining factors but mostly instructed by the local environment (29-31) as even mature macrophages adoptively transferred can be reprogrammed by the tissue to a certain extent $(32,33)$. Little information is available regarding the functional identity of MoD-ResMac and EmD-ResMac (34), but evidence show that macrophages derived from classical monocytes (named here MoD-Mac) infiltrating the tissue in an inflammatory context harbor distinct transcriptomic profiles, display shorter life span [reviewed in Guilliams et al. (35)] and can be functionally distinct (36).

\section{RECONSIDERING TAM ORIGIN}

The characterization of macrophage ontogeny in tissue at steady state has rapidly raised the question of their presence in neoplastic tissues and their differential role in tumor development.

Until recently, TAM were considered to originate exclusively from monocyte precursors undergoing differentiation upon tissue infiltration but the distinction of TAM from different origins led us to reconsider this dogma (37-39). In most cancer models, blocking the CCL2/CCR2 axis leads to a strong decrease in TAM abundance. Because CCR2 is a major receptor involved in monocyte trafficking, it has contributed to the idea that TAM originate from bone marrow-derived CCR2 ${ }^{+}$monocyte precursors (40-42). In an inducible lung carcinoma model, splenectomy resulted in a strong reduction in TAM. These spleen-derived TAM were shown to be also CCR2-dependent, suggesting that CCR2-deficiency does not necessarily account for a direct bone marrow provenance of TAM progenitors (43). However, deletion of Ccr2 did not result in full depletion of macrophages suggesting that a CCR2-independent TAM accumulation or compensatory mechanisms might exist. CCR2deficiency did not impact the relative proportion of TAM in the spontaneous PyMT-MMTV mammary carcinoma, but the use of $C c r 2^{D T R}$ system led to an almost complete elimination of TAM suggesting their monocytic origin (44). However, CCR2 expression by ResTAM could not be excluded, and would also sensitize them to the toxin.

Recent studies have confirmed that TAM of different origins accumulate within the TME in mouse cancer models. Using parabiotic mice and bone marrow transfer, it was shown that the pool of TAM was composed of both newly recruited MoD-Mac and ResMac in a model of pancreatic ductal adenocarcinoma. Fate mapping models strongly support that a significant fraction of these ResTAM have embryonic origin and actively proliferate along with tumor growth (38). Although no difference in tumor weight was observed in $\mathrm{Ccr} 2^{-/-}$mice, ResTAM depletion using anti-CSF1R antibody and clodronate was associated with a strong reduction of tumor burden suggesting a dominant role of this population in tumor growth (38). 


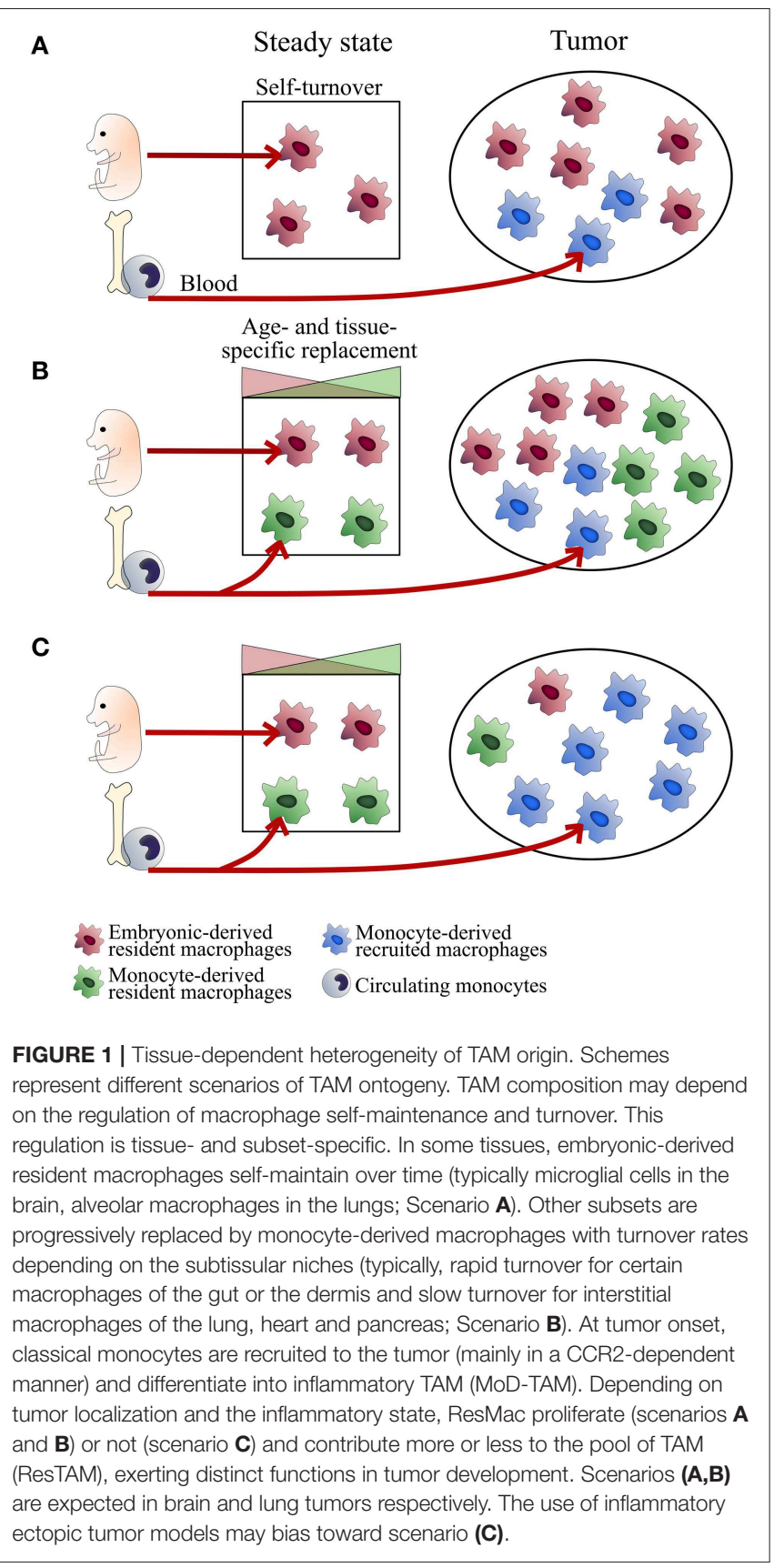

The expansion of resident interstitial macrophages with the development of multifocal lung tumors was also observed by Loyher et al. (37). Fate mapping experiments unveiled that at least a fraction of these TAM had an embryonic origin and greatly expand with tumor development. Interestingly AM, the typical embryonic-derived macrophages in the lung, did not expand and the relative proportion of ResTAM and recruited MoD-TAM was dependent on the anatomical niche of tumor development (37).

In the brain, conflicting results have been published regarding TAM origin (45). Microglial cells were shown to be the major contributor in several studies whereas others supported an accumulation of MoD-TAM (46-48). As several models used irradiation to test whether classical monocytes were able to replenish the brain, the disruption of the blood brain barrier may have artificially increased the accumulation of MoDTAM $(34,49)$. Major contribution of this last population was demonstrated in primary and metastatic brain tumors (39). Different transcriptional profiles as well as different epigenetic landscapes were observed between microglia and MoD-TAM, associated with different activation patterns. The comparison with macrophages from healthy brain tissue revealed that some features shared by both TAM populations were not dependent on ontogeny but were "taught" by the TME. Additionally, CD49d was identified as a potent marker to discriminate microgliavs. MoD-TAM in both murine models and human brain tumors (39).

Based on this work, single cell RNA sequencing was performed on macrophages from glioma or non-malignant human tissues (50). From 237 lineage-specific murine TAM genes, they compared the homologous genes in human samples and identified two TAM subsets that correlated with microglial enriched or bone marrow-derived TAM enriched genes. These two profiles were thus hypothesized to reflect the differential ontogeny of TAM in human brain tumors (50).

\section{ONTOGENY AS A NEW FEATURE OF TAM DIVERSITY}

So far, few works support that TAM can be composed of newly recruited MoD-TAM mostly in a CCR2-dependent manner, but also ResTAM of embryonic origin (EmD-ResTAM) or arising from adult hematopoiesis (MoD-ResTAM) that locally proliferate and accumulate with tumor expansion. Whether this assumption can be generalized to other models deserve further investigation and the transposition to human tumors is even more hypothetical due to the lack of knowledge in macrophage ontogeny. Combining fate mapping models with RNA sequencing from mice to identify specific signature based on homologous human genes might be a valuable approach to track macrophage ontogeny in humans.

According to the model proposed for macrophages niches at steady state (23), the relative proportion of the different TAM subsets may vary with age, organs, subtissular niches, and the inflammatory state of tumor development (Figure 1). Understanding the relative importance of ResMac vs. MoD-Mac in the pool of TAM is limited by the lack of clear markers to discriminate them both in mice and human. Moreover, the use of experimental ectopic tumor models inducing local inflammation could bias the composition of the TAM compartment (scenario C in Figure 1). Ontogeny may represent a source of heterogeneity, hence an alternative classification in TAM diversity in addition to the common M1/M2 nomenclature.

\section{THE M1/M2 NOMENCLATURE MODEL IN TAM ORIGIN}

The common characterization of TAM subsets relies on the M1/M2 polarization model induced by different in vitro 
stimuli (18). This model rapidly finds limitation in complex environments (in vivo) in which M1 and M2 stimuli can be present and generate very dynamic microanatomical niches. Tumors should be considered as an evolving tissue in which space availability and growth factors expression are changing over time $(51,52)$ and where inflammatory signals are generated by the loss of tissue integrity and immune cell infiltration (53). It is thus not surprising to find a wide range of activation profiles in the TME $(18-20,45)$. No typical M1/M2-associated marker defined one or the other TAM subset in lung unveiling heterogeneity among each subset (37). No direct link between TAM origin and the commonly described pro- or anti-tumor profile could be achieved in this study. One could expect that macrophage ontogeny and their anatomic localization define specific niches dictating their polarization toward a specific phenotype and function.

\section{TAM FUNCTION ACCORDING TO THEIR ORIGIN}

Despite recent works discriminating resident TAM vs. recruited TAM, their relative function in the TME has been barely addressed. The absence of phenotypic markers defining TAM according to their origin limits the possibility for functional studies. As previously mentioned, Ccr2 deletion has been very useful to generate a TME with a largely reduced infiltration of recruited MoD-TAM while ResTAM seemed to be less affected. The variable extent of macrophage deletion observed between the different models may be related to the relative proportion of resident and recruited TAM. In most cases, the impaired macrophage accumulation in the TME was associated with a better control of the tumor and reduced metastatic dissemination (54-57) suggesting a major role for MoD-TAM in these processes. For instance, no difference in lung tumor burden was observed in CCR2-deficient mice compared to WT although nodules were smaller and more disperse suggesting that both MoD-TAM and ResTAM contributed to tumor growth but the presence of the former was associated with increased tumor cell spreading (37). Accordingly, CCL2 secretion by breast tumor cells activated Wnt-1 production by mammary intraepithelial macrophages inducing an epithelial/mesenchymal transition-like signaling on cancer cells and driving early cancer dissemination (58).

In $\mathrm{Ccr} 2^{-/}$mice engrafted with colorectal cancer, the reduction in TAM was associated with reduced tumor burden along with altered ECM composition (59). Genomic and proteomic analyses revealed upregulation of collagen synthesis and deposition in monocytes differentiating into TAM. CCR2dependent TAM were shown to have a primary role in shaping the TME, thus promoting tumor expansion. On the other hand, Madsen and colleagues showed that CCR2 ${ }^{+}$MoD-TAM were responsible for collagen degradation in the TME in various tumor models. Transcriptomic analysis of these cells revealed a catabolic signature related to ECM degradation in this subset (60). These paradoxical observations suggest that different CCR2-dependent TAM subsets might be implicated in deposition and degradation of collagen in the TME. However, Res-TAM from pancreatic ductal adenocarcinoma were also shown to exhibit a pro-fibrotic profile, with increased expression of genes involved in ECM deposition and remodeling, which is a hallmark of this cancer. On the other hand, MoD-TAM were more efficient antigenpresenting cells (38).

Finally, in brain tumor, microglial-cells were enriched in pro-inflammatory genes as well as factors involved in ECM remodeling while MoD-TAM exhibited an immunosuppressive signature associated with immune suppression (39). In human glioma samples, MoD-TAM infiltration correlates with tumor grade. These TAM also exhibit an immunosuppressive profile with increased immunosuppressive cytokine expression. As observed by Chen et al. in a mouse model (61), these cells localize in necrotic regions and perivascular areas while microgliaderived TAM were found at the edge of the tumor (50).

Altogether, most studies rely on transcriptomic analysis and highlight functional profiles of resident vs. recruited TAM that cannot be fully associated with their origin across the different models. In addition, very little information is available regarding suppression of the adaptive response which is a key feature of TAM biology. Functional differences might be linked with the differential cues from the TME that polarize the macrophages in a niche-specific manner in addition to their ontogenyspecific features. Live imaging studies represent a complementary approach to compare functional difference between TAM subsets as reported in the lungs (37) and recently in the brain (62). Further studies using fluorescent strains and lineage-tracing models (63) will be necessary to better address the functional features of TAM subsets to better understand their role in tumor development as well as resistance to anti-cancer therapies and unveil key target for immunotherapy.

\section{RESPONSE OF TAM SUBSETS TO ANTI-CANCER THERAPIES}

Apart from their direct impact on tumor cells anti-cancer therapies display many immune-mediated effects. In addition to conventional treatments, many immunotherapies to boost the anti-tumor immune response are under investigation. TAM are usually considered as a factor of resistance to many therapies (6466) but paradoxical roles in their efficacy are reported. Whether these contrasting roles are related to their ontogeny is unknown. Therefore, elucidating how TAM subsets are impacted by anticancer treatments is crucial especially in the context of combined therapies. So far, very few studies have addressed the selective targeting of TAM from different origins.

Following myeloablative chemotherapy using cyclophosphamide, we showed that both resident and recruited TAM were depleted by the alkylating agent in lung tumor (37). Recruited TAM rapidly recovered through a transient and massive wave of bone marrow-derived monocytes and TAM, while ResTAM recovery was much more limited. This wave contributed to tumor cell destruction and phagocytosis suggesting that in certain cases TAM are potent effector of the anti-tumor response. Specific targeting of TAM displaying 
protumor function without affecting tumoricidal activity is thus required in these conditions.

For instance, anti-CSF1R is quite efficient to deplete TAM in both human and mouse tumors (67) but its clinical efficacy is limited and leads to compensatory mechanisms (68). Mouse models suggest that anti-CSF1R treatment depletes efficiently certain subsets of ResMac but its effect on monocytes showed conflicting results that could be explained by variable dependency on CSF1R across different tumor microenvironment $(45,69$, 70). In a lung tumor model, anti-CSF1R treatment blocked monocyte accumulation and differentiation into MHC-II ${ }^{\text {lo }} \mathrm{TAM}$, indicating a role for this axis in monocyte recruitment beyond CCL2/CCR2 (69). However, the impact on tumor growth was not reported. Another study in the lung showed strong depletion of TAM following anti-CSF1R administration although monocytes were not affected (70). No effect on tumor growth was observed, suggesting either that ResTAM are irrelevant to tumor growth or that some macrophage subsets involved in anti-tumor response could also be depleted. These studies were performed with different anti-CSF1R clones, which might have different pharmacological action.

PD1/PDL1 represents another promising approach to target macrophages as PD1 expression by macrophages increases along tumor growth (71). Anti-PD1 therapy was shown to induce a macrophage-dependent anti-tumor efficacy in a subcutaneous injected colon cancer cell line (71). Using bone marrow transplant of $\mathrm{RFP}^{+}$cells it was shown that $\mathrm{PD}^{+}$TAM were mainly of medullar origin, although the use of fully reconstituted irradiated chimera may impact the compartment of resident MoD-TAM.

Restoring antigen presentation in the TME is essential to induce an effective T-cell anti-tumor response (72). The SIRP $\alpha / C D 47$ signaling axis is a "don't eat me" signal that is being hijacked by tumor cells to abrogate phagocytosis by TAM, thus impairing antigen processing. CD47 has been shown to be overexpressed in several cancer indications. Immunotherapy targeting CD47 has shown promising results in various tumors, including brain tumors $(11,73,74)$. CD47 blockade was tested in glioblastoma pre-clinical models and showed a differential response of ResTAM vs. MoD-TAM. Both subsets showed

\section{REFERENCES}

1. Cassetta L, Pollard JW. Targeting macrophages: therapeutic approaches in cancer. Nat Rev Drug Discov. (2018) 17:887-904. doi: 10.1038/nrd.2018.169

2. Sidibe A, Ropraz P, Jemelin S, Emre Y, Poittevin M, Pocard M, et al. Angiogenic factor-driven inflammation promotes extravasation of human proangiogenic monocytes to tumours. Nat Commun. (2018) 9:355. doi: 10.1038/s41467-017-02610-0

3. Kerkelä E, Ala-aho R, Jeskanen L, Rechardt O, Grénman R, Shapiro $\mathrm{SD}$, et al. Expression of human macrophage metalloelastase (MMP-12) by tumor cells in skin cancer. J Invest Dermatol. (2000) 114:1113-9. doi: 10.1046/j.1523-1747.2000.00993.x

4. Tang C-H, Tsai C-C. CCL2 increases MMP-9 expression and cell motility in human chondrosarcoma cells via the Ras/Raf/MEK/ERK/NFкB signaling pathway. Biochem Pharmacol. (2012) 83:335-44. doi: $10.1016 /$ j.bcp.2011.11.013 enhanced phagocytosis upon treatment, but microglia-derived TAM displayed less inflammatory response. This was associated with prolonged mouse survival. The anti-CD47 effect on microglia was maintained in CCR2-deficient mice although the survival did not reach the same value as in WT mice (75). These results indicate that microglia-derived TAM might be the main subset involved in antigen presentation to T-cell in glioblastoma.

The development of immunotherapies targeting the myeloid compartment is challenging as targeting TAM is a doubleedged sword process and the selective depletion of pro-tumoral macrophages without affecting the anti-tumor function would be idealistic.

\section{CONCLUDING REMARKS}

The characterization of TAM ontogeny is still in its infancy. The lack of specific markers to discriminate and selectively target them for functional studies represents a technical limitation. Fate-mapping models and fluorescent reporters have revealed a differential contribution of tissue-resident and inflammatory macrophages in the pool of TAM in several tumor models, but no specific functional profile could be attributed to their origin across different cancer indication so far. Indeed, the contribution of TAM subsets follows complex spatio-temporal dynamics as macrophage niches evolves throughout life with specific regulation at the subtissular level depending on the organ and the age. Better characterization of how these subsets are differentially affected by anti-cancer therapy is of major importance to be able to selectively target them and thus promote the anti-tumor immune response.

\section{AUTHOR CONTRIBUTIONS}

ML and $\mathrm{AB}$ wrote the manuscript.

\section{FUNDING}

This work was supported by Fondation ARC pour la recherche sur le cancer, l'INCa (2018-1-PLBIO-06-1) and DIM Malinf. ML was supported by Sorbonne University program Idex SUPER.
5. Ojalvo LS, Whittaker CA, Condeelis JS, Pollard JW. Gene expression analysis of macrophages that facilitate tumor invasion supports a role for Wntsignaling in mediating their activity in primary mammary tumors. J Immunol. (2010) 184:702-12. doi: 10.4049/jimmunol.0902360

6. Hughes R, Qian B-Z, Rowan C, Muthana M, Keklikoglou I, Olson OC, et al. Perivascular M2 macrophages stimulate tumor relapse after chemotherapy. Cancer Res. (2015) 75:3479-91. doi: 10.1158/0008-5472.CAN-14-3587

7. Qian B, Deng Y, Im JH, Muschel RJ, Zou Y, Li J, et al. A distinct macrophage population mediates metastatic breast cancer cell extravasation, establishment and growth. PLoS ONE. (2009) 4:e6562. doi: 10.1371/journal.pone.0006562

8. Qian B, Pollard JW. Macrophage diversity enhances tumor progression and metastasis. Cell. (2010) 141:39-51. doi: 10.1016/j.cell.2010.03.014

9. Zhang Q, Liu L, Gong C, Shi H, Zeng Y, Wang X, et al. Prognostic significance of tumor-associated macrophages in solid tumor: a meta-analysis of the literature. PLoS ONE. (2012) 7:e50946. doi: 10.1371/journal.pone.00 50946 
10. Beatty GL, Chiorean EG, Fishman MP, Saboury B, Teitelbaum UR, Sun W, et al. CD40 agonists alter tumor stroma and show efficacy against pancreatic carcinoma in mice and humans. Science. (2011) 331:1612-6. doi: $10.1126 /$ science. 1198443

11. Willingham SB, Volkmer J-P, Gentles AJ, Sahoo D, Dalerba P, Mitra SS, et al. The CD47-signal regulatory protein alpha (SIRPa) interaction is a therapeutic target for human solid tumors. Proc Natl Acad Sci USA. (2012) 109:6662-7. doi: 10.1073/pnas.1121623109

12. Thoreau M, Penny HL, Tan K, Regnier F, Weiss JM, Lee B, et al. Vaccineinduced tumor regression requires a dynamic cooperation between $\mathrm{T}$ cells and myeloid cells at the tumor site. Oncotarget. (2015) 6:27832-46. doi: 10.18632/oncotarget.4940

13. van Furth R, Cohn ZA, Hirsch JG, Humphrey JH, Spector WG, Langevoort HL. The mononuclear phagocyte system: a new classification of macrophages, monocytes, and their precursor cells. Bull World Health Organ. (1972) 46:845-52.

14. Ginhoux F, Guilliams M. Tissue-resident macrophage ontogeny and homeostasis. Immunity. (2016) 44:439-49. doi: 10.1016/j.immuni.2016.02.024

15. Hoeffel G, Ginhoux F. Ontogeny of tissue-resident macrophages. Front Immunol. (2015) 6:486. doi: 10.3389/fimmu.2015.00486

16. Geissmann F, Gordon S, Hume DA, Mowat AM, Randolph GJ. Unravelling mononuclear phagocyte heterogeneity. Nat Rev Immunol. (2010) 10:453-60. doi: $10.1038 /$ nri2784

17. Mantovani A, Sica A, Sozzani S, Allavena P, Vecchi A, Locati M. The chemokine system in diverse forms of macrophage activation and polarization. Trends Immunol. (2004) 25:677-86. doi: 10.1016/j.it.2004.09.015

18. Martinez FO, Gordon S. The M1 and M2 paradigm of macrophage activation: time for reassessment. F1000Prime Rep. (2014) 6:13. doi: 10.12703/P6-13

19. Murray PJ, Allen JE, Biswas SK, Fisher EA, Gilroy DW, Goerdt S, et al. Macrophage activation and polarization: nomenclature and experimental guidelines. Immunity. (2014) 41:14-20. doi: 10.1016/j.immuni.2014.06.008

20. Xue J, Schmidt SV, Sander J, Draffehn A, Krebs W, Quester I, et al. Transcriptome-based network analysis reveals a spectrum model of human macrophage activation. Immunity. (2014) 40:274-88. doi: 10.1016/j.immuni.2014.01.006

21. Salmon H, Remark R, Gnjatic S, Merad M. Host tissue determinants of tumour immunity. Nat Rev Cancer. (2019) 19:215-27. doi: 10.1038/s41568-019-0125-9

22. Chakarov S, Lim HY, Tan L, Lim SY, See P, Lum J, et al. Two distinct interstitial macrophage populations coexist across tissues in specific subtissular niches. Science. (2019) 363:eaau0964. doi: 10.1126/science.aau0964

23. Guilliams M, Scott CL. Does niche competition determine the origin of tissue-resident macrophages? Nat Rev Immunol. (2017) 17:451-60. doi: $10.1038 /$ nri.2017.42

24. Hambardzumyan D, Bergers G. Glioblastoma: Defining tumor niches. Trends Cancer. (2015) 1:252-65. doi: 10.1016/j.trecan.2015.10.009

25. De Schepper S, Verheijden S, Aguilera-Lizarraga J, Viola MF, Boesmans $\mathrm{W}$, Stakenborg $\mathrm{N}$, et al. Self-maintaining gut macrophages are essential for intestinal homeostasis. Cell. (2018) 175:400-15.e13. doi: 10.1016/j.cell.2018.07.048

26. Guilliams M, De Kleer I, Henri S, Post S, Vanhoutte L, De Prijck S, et al. Alveolar macrophages develop from fetal monocytes that differentiate into long-lived cells in the first week of life via GM-CSF. J Exp Med. (2013) 210:1977-92. doi: 10.1084/jem.20131199

27. Tan SYS, Krasnow MA. Developmental origin of lung macrophage diversity. Development. (2016) 143:1318-27. doi: 10.1242/dev.129122

28. Gibbings SL, Thomas SM, Atif SM, McCubbrey AL, Desch AN, Danhorn T, et al. Three unique interstitial macrophages in the murine lung at steady state. Am J Respir Cell Mol Biol. (2017) 57:66-76. doi: 10.1165/rcmb.2016-0361OC

29. T'Jonck W, Guilliams M, Bonnardel J. Niche signals and transcription factors involved in tissue-resident macrophage development. Cell Immunol. (2018) 330:43-53. doi: 10.1016/j.cellimm.2018.02.005

30. Gibbings SL, Goyal R, Desch AN, Leach SM, Prabagar M, Atif SM, et al. Transcriptome analysis highlights the conserved difference between embryonic and postnatal-derived alveolar macrophages. Blood. (2015) 126:1357-66. doi: 10.1182/blood-2015-01-624809

31. Gosselin D, Link VM, Romanoski CE, Fonseca GJ, Eichenfield DZ, Spann NJ, et al. Environment drives selection and function of enhancers controlling tissue-specific macrophage identities. Cell. (2014) 159:1327-40. doi: 10.1016/j.cell.2014.11.023

32. Lavin Y, Winter D, Blecher-Gonen R, David E, Keren-Shaul H, Merad M, et al. Tissue-resident macrophage enhancer landscapes are shaped by the local microenvironment. Cell. (2014) 159:1312-26. doi: 10.1016/j.cell.2014.11.018

33. van de Laar L, Saelens W, De Prijck S, Martens L, Scott CL, Van Isterdael $\mathrm{G}$, et al. Yolk sac macrophages, fetal liver, and adult monocytes can colonize an empty niche and develop into functional tissue-resident macrophages. Immunity. (2016) 44:755-68. doi: 10.1016/j.immuni.2016.02.017

34. Cronk JC, Filiano AJ, Louveau A, Marin I, Marsh R, Ji E, et al. Peripherally derived macrophages can engraft the brain independent of irradiation and maintain an identity distinct from microglia. J Exp Med. (2018) 215:162747. doi: 10.1084/jem.20180247

35. Guilliams M, Mildner A, Yona S. Developmental and functional heterogeneity of monocytes. Immunity. (2018) 49:595-613. doi: 10.1016/j.immuni.2018.10.005

36. Mould KJ, Barthel L, Mohning MP, Thomas SM, McCubbrey AL, Danhorn $\mathrm{T}$, et al. Cell origin dictates programming of resident versus recruited macrophages during acute lung injury. Am J Respir Cell Mol Biol. (2017) 57:294-306. doi: 10.1165/rcmb.2017-0061OC

37. Loyher P-L, Hamon P, Laviron M, Meghraoui-Kheddar A, Goncalves E, Deng $\mathrm{Z}$, et al. Macrophages of distinct origins contribute to tumor development in the lung. J Exp Med. (2018) 215:2536-53. doi: 10.1084/jem.20180534

38. Zhu Y, Herndon JM, Sojka DK, Kim K-W, Knolhoff BL, Zuo C, et al. Tissueresident macrophages in pancreatic ductal adenocarcinoma originate from embryonic hematopoiesis and promote tumor progression. Immunity. (2017) 47:323-38.e6. doi: 10.1016/j.immuni.2017.07.014

39. Bowman RL, Klemm F, Akkari L, Pyonteck SM, Sevenich L, Quail $\mathrm{DF}$, et al. Macrophage ontogeny underlies differences in tumorspecific education in brain malignancies. Cell Rep. (2016) 17:2445-59. doi: 10.1016/j.celrep.2016.10.052

40. Mondini M, Loyher P-L, Hamon P, Gerbé de Thoré M, Laviron M, Berthelot $\mathrm{K}$, et al. CCR2-dependent recruitment of tregs and monocytes following radiotherapy is associated with $\mathrm{TNF} \alpha$-mediated resistance. Cancer Immunol Res. (2019) 7:376-87. doi: 10.1158/2326-6066.CIR-18-0633

41. Conti I, Rollins BJ. CCL2 (monocyte chemoattractant protein-1) and cancer. Semin Cancer Biol. (2004) 14:149-54. doi: 10.1016/j.semcancer.2003.10.009

42. Kalbasi A, Komar C, Tooker GM, Liu M, Lee JW, Gladney WL, et al. Tumor-derived CCL2 mediates resistance to radiotherapy in pancreatic ductal adenocarcinoma. Clin Cancer Res. (2017) 23:137-48. doi: 10.1158/1078-0432.CCR-16-087fv0

43. Cortez-Retamozo V, Etzrodt M, Newton A, Rauch PJ, Chudnovskiy A, Berger C, et al. Origins of tumor-associated macrophages and neutrophils. Proc Natl Acad Sci USA. (2012) 109:2491-6. doi: 10.1073/pnas.1113744109

44. Franklin RA, Liao W, Sarkar A, Kim MV, Bivona MR, Liu K, et al. The cellular and molecular origin of tumor-associated macrophages. Science. (2014) 344:921-5. doi: 10.1126/science. 1252510

45. Hambardzumyan D, Gutmann DH, Kettenmann H. The role of microglia and macrophages in glioma maintenance and progression. Nat Neurosci. (2016) 19:20-27. doi: 10.1038/nn.4185

46. Zhou W, Ke SQ, Huang Z, Flavahan W, Fang X, Paul J, et al. Periostin secreted by glioblastoma stem cells recruits M2 tumour-associated macrophages and promotes malignant growth. Nat Cell Biol. (2015) 17:17082. doi: $10.1038 /$ ncb3090

47. Parney IF, Waldron JS, Parsa AT. Flow cytometry and in vitro analysis of human glioma-associated macrophages. Laboratory investigation. $J$ Neurosurg. (2009) 110:572-82. doi: 10.3171/2008.7.JNS08475

48. Müller A, Brandenburg S, Turkowski K, Müller S, Vajkoczy P. Resident microglia, and not peripheral macrophages, are the main source of brain tumor mononuclear cells. Int J Cancer. (2015) 137:278-88. doi: 10.1002/ijc.29379

49. Mildner A, Schmidt H, Nitsche M, Merkler D, Hanisch U-K, Mack M, et al. Microglia in the adult brain arise from Ly-6ChiCCR2 + monocytes only under defined host conditions. Nat Neurosci. (2007) 10:1544-53. doi: $10.1038 / \mathrm{nn} 2015$

50. Müller S, Kohanbash G, Liu SJ, Alvarado B, Carrera D, Bhaduri A, et al. Single-cell profiling of human gliomas reveals macrophage ontogeny as a basis for regional differences in macrophage activation 
in the tumor microenvironment. Genome Biol. (2017) 18:234. doi: 10.1186/s13059-017-1362-4

51. Witsch E, Sela M, Yarden Y. Roles for growth factors in cancer progression. Physiology. (2010) 25:85-101. doi: 10.1152/physiol.00045.2009

52. Lyssiotis CA, Kimmelman AC. Metabolic interactions in the tumor microenvironment. Trends Cell Biol. (2017) 27:863-75. doi: 10.1016/j.tcb.2017.06.003

53. Mantovani A, Allavena P, Sica A, Balkwill F. Cancer-related inflammation. Nature. (2008) 454:436-44. doi: 10.1038/nature07205

54. Lim SY, Yuzhalin AE, Gordon-Weeks AN, Muschel RJ. Targeting the CCL2CCR2 signaling axis in cancer metastasis. Oncotarget. (2016) 7:28697-710. doi: 10.18632/oncotarget.7376

55. Qian B-Z, Li J, Zhang H, Kitamura T, Zhang J, Campion LR, et al. CCL2 recruits inflammatory monocytes to facilitate breast tumor metastasis. Nature. (2011) 475:222-5. doi: 10.1038/nature10138

56. Sanford DE, Belt BA, Panni RZ, Mayer A, Deshpande AD, Carpenter D, et al. Inflammatory monocyte mobilization decreases patient survival in pancreatic cancer: a role for targeting the CCL2/CCR2 axis. Clin Cancer Res. (2013) 19:3404-15. doi: 10.1158/1078-0432.CCR-13-0525

57. Loberg RD, Ying C, Craig M, Yan L, Snyder LA, Pienta KJ. CCL2 as an important mediator of prostate cancer growth in vivo through the regulation of macrophage infiltration. Neoplasia. (2007) 9:556-62. doi: 10.1593/neo.07307

58. Linde N, Casanova-Acebes M, Sosa MS, Mortha A, Rahman A, Farias E, et al. Macrophages orchestrate breast cancer early dissemination and metastasis. Nat Commun. (2018) 9:21. doi: 10.1038/s41467-017-02481-5

59. Afik R, Zigmond E, Vugman M, Klepfish M, Shimshoni E, Pasmanik-Chor $\mathrm{M}$, et al. Tumor macrophages are pivotal constructors of tumor collagenous matrix. J Exp Med. (2016) 213:2315-31. doi: 10.1084/jem.20151193

60. Madsen DH, Jürgensen HJ, Siersbæk MS, Kuczek DE, Grey Cloud L, Liu S, et al. Tumor-associated macrophages derived from circulating inflammatory monocytes degrade collagen through cellular uptake. Cell Rep. (2017) 21:3662-71. doi: 10.1016/j.celrep.2017.12.011

61. Chen Z, Feng X, Herting CJ, Garcia VA, Nie K, Pong WW, et al. Cellular and molecular identity of tumor-associated macrophages in glioblastoma. Cancer Res. (2017) 77:2266-78. doi: 10.1158/0008-5472.CAN-16-2310

62. Chen Z, Ross JL, Hambardzumyan D. Intravital 2-photon imaging reveals distinct morphology and infiltrative properties of glioblastomaassociated macrophages. Proc Natl Acad Sci USA. (2019) 116:14254-59. doi: $10.1073 /$ pnas. 1902366116

63. Laviron M, Combadière C, Boissonnas A. Tracking monocytes and macrophages in tumors with live imaging. Front Immunol. (2019) 10:1201. doi: 10.3389/fimmu.2019.01201

64. Long KB, Collier AI, Beatty GL. Macrophages: key orchestrators of a tumor microenvironment defined by therapeutic resistance. Mol Immunol. (2017) 110:3-12. doi: 10.1016/j.molimm.2017.12.003

65. Chen L, Li J, Wang F, Dai C, Wu F, Liu X, et al. Tie2 expression on macrophages is required for blood vessel reconstruction and tumor relapse after chemotherapy. Cancer Res. (2016) 76:6828-38. doi: 10.1158/0008-5472.CAN-16-1114
66. Yang M, McKay D, Pollard JW, Lewis CE. Diverse functions of macrophages in different tumor microenvironments. Cancer Res. (2018) 78:5492-503. doi: 10.1158/0008-5472.CAN-18-1367

67. Ries $\mathrm{CH}$, Hoves S, Cannarile MA, Rüttinger D. CSF-1/CSF-1R targeting agents in clinical development for cancer therapy. Curr Opin Pharmacol. (2015) 23:45-51. doi: 10.1016/j.coph.2015.05.008

68. Kumar V, Donthireddy L, Marvel D, Condamine T, Wang F, Lavilla-Alonso S, et al. Cancer-associated fibroblasts neutralize the anti-tumor effect of CSF1 receptor blockade by inducing PMN-MDSC infiltration of tumors. Cancer Cell. (2017) 32:654-68.e5. doi: 10.1016/j.ccell.2017.10.005

69. Van Overmeire E, Stijlemans B, Heymann F, Keirsse J, Morias Y, Elkrim Y, et al. M-CSF and GM-CSF receptor signaling differentially regulate monocyte maturation and macrophage polarization in the tumor microenvironment. Cancer Res. (2016) 76:35-42. doi: 10.1158/0008-5472.CAN-15-0869

70. MacDonald KPA, Palmer JS, Cronau S, Seppanen E, Olver S, Raffelt NC, et al. An antibody against the colony-stimulating factor 1 receptor depletes the resident subset of monocytes and tissue- and tumor-associated macrophages but does not inhibit inflammation. Blood. (2010) 116:3955-63. doi: 10.1182/blood-2010-02-266296

71. Gordon SR, Maute RL, Dulken BW, Hutter G, George $\mathrm{BM}$, McCracken MN, et al. PD-1 expression by tumourassociated macrophages inhibits phagocytosis and tumour immunity. Nature. (2017) 545:495-99. doi: 10.1038/nature 22396

72. Cassetta L, Kitamura T. Macrophage targeting: opening new possibilities for cancer immunotherapy. Immunology. (2018) 155:285-93. doi: 10.1111/imm.12976

73. Gholamin S, Mitra SS, Feroze AH, Liu J, Kahn SA, Zhang M, et al. Disrupting the CD47-SIRP $\alpha$ anti-phagocytic axis by a humanized anti-CD47 antibody is an efficacious treatment for malignant pediatric brain tumors. Sci Transl Med. (2017) 9:eaaf2968. doi: 10.1126/scitranslmed.aaf2968

74. Chao MP, Alizadeh AA, Tang C, Myklebust JH, Varghese B, Gill $\mathrm{S}$, et al. Anti-CD47 antibody synergizes with rituximab to promote phagocytosis and eradicate non-Hodgkin lymphoma. Cell. (2010) 142:699713. doi: $10.1016 /$ j.cell.2010.07.044

75. Hutter G, Theruvath J, Graef CM, Zhang M, Schoen MK, Manz EM, et al. Microglia are effector cells of CD47-SIRP $\alpha$ antiphagocytic axis disruption against glioblastoma. Proc Natl Acad Sci USA. (2019) 116:9971006. doi: $10.1073 /$ pnas. 1721434116

Conflict of Interest Statement: The authors declare that the research was conducted in the absence of any commercial or financial relationships that could be construed as a potential conflict of interest.

Copyright $\odot 2019$ Laviron and Boissonnas. This is an open-access article distributed under the terms of the Creative Commons Attribution License (CC BY). The use, distribution or reproduction in other forums is permitted, provided the original author(s) and the copyright owner(s) are credited and that the original publication in this journal is cited, in accordance with accepted academic practice. No use, distribution or reproduction is permitted which does not comply with these terms. 